\title{
A Small Organic Catalyst Based on Benzothiadiazole for Electrocatalytic Hydrogen Production
}

\author{
Martin Axelsson $^{1}$, Cleber F. N. Marchiori ${ }^{2}$, Ping Huang ${ }^{1}$, C. Moyses Araujo ${ }^{2,3}$ and Haining Tian ${ }^{1, *}$ \\ ${ }^{1}$ Department of Chemistry-Ångström Laboratory, Uppsala University, SE 75120 Uppsala, Sweden; \\ ${ }^{2}$ Department of Engineering and Physics, Karlstad University, 65188 Karlstad, Sweden \\ ${ }^{3}$ Department of Physics and Astronomy, Ångström Laboratory, Uppsala University, 75120 Uppsala, Sweden
}

\begin{abstract}
A small organic molecule 2,1,3-benzothiadiazole-4, 7-dicarbonitrile (BTDN) is assessed as a hydrogen evolution electrocatalyst, showing a hydrogen production faradaic efficiency of $82 \%$ in presence of salicylic acid. The key catalytic intermediates of reduced species $\mathrm{BTDN}^{-}$and organo-hydride species $\mathrm{BTDNH}^{-}$are identified and characterized by using various spectroscopic methods and density functional theory (DFT) based calculations. With the experimental and theoretical results, a catalytic mechanism of BTDN for electrocatalytic $\mathrm{H}_{2}$ evolution is proposed.
\end{abstract}

Using photocatalysis and electrocatalysis for generation of clean and renewable fuels from abundant resources such as water and $\mathrm{CO}_{2}$ is one of the most promising directions for replacing fossil fuels ${ }^{1}$. Development of low-cost, efficient and environmental-friendly catalysts is therefore vital. To date, the catalysts for these processes are commonly metal complexes ${ }^{2-3}$, and metal and organic materials ${ }^{4-5}$. While often being utilized as ligands in metal complexes or building blocks in organic materials, small organic molecules as catalysts for these types of redox reactions are not well studied. Recently, small, aromatic and nitrogen rich organic compounds have been demonstrated to facilitate both water oxidation ${ }^{6-7}$ and $\mathrm{CO}_{2}$ reduction ${ }^{8-12}$. When it comes to hydrogen evolution, there are very few reported cases that we know of ${ }^{13}$. 2,1,3-benzothiadiazole (BT) has been used as a popular electron acceptor blocking unit in many organic polymers for photocatalysis and we previously have proposed that BT could be an active site for hydrogen production without addition of any co-catalyst in polymer dots photocatalyst ${ }^{14-16}$. In this work, we experimentally and theoretically assessed a BT derivative 2,1,3-benzothiadiazole-4, 7-dicarbonitrile (BTDN, see Scheme 1) as a small organic catalyst and investigated the mechanism for electrocatalytic hydrogen production.

BTDN has two nitrile- $(\mathrm{CN})$ groups at its 4 and 7 positions which can lower its reduction potentials as compared to BT. The $\mathrm{CN}$ units also have characteristic absorption in infrared (IR) region which is vital for monitoring reaction intermediates from IR spectrum in the following study. Inspired by the study from Cole-Hamilton and co-authors on the photochemical properties of BTDN in micelles ${ }^{19-21}$, we studied BTDN's electro-catalytic properties in the work. The electrochemical behaviour of BTDN is evaluated by cyclic voltammetry $(\mathrm{CV})$, rendering two fully reversible redox waves at $-1.06 \mathrm{~V}$ and $-1.88 \mathrm{~V}$ vs Ferrocene/Ferrocenium $\left(\mathrm{Fc} / \mathrm{Fc}^{+}\right)$in acetonitrile, as shown in Figure 1. The two redox events represent the reduction of BTDN to its anionic radical species $\mathrm{BTDN}^{-}$and doubly reduced species $\mathrm{BTDN}^{2-}$, respectively. In order to check if the reduced species of BTDN can interact with proton(s), salicylic acid (SAL) with $\mathrm{pK}_{\mathrm{a}}$ of 16.7 in acetonitrile $(\mathrm{AcN})^{22}$, is selected as an organic acid for this experiment after comparing with Trifluoroacetic acid and Acetic acid (Figure S1). SAL offers a broad electrochemical window which allows us to observe the catalytic behaviour of BTDN in presence of protons, but with negligible background current from bare SAL on glassy carbon (Figure S2).

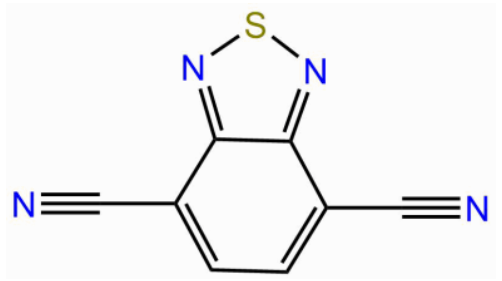

Scheme 1: The molecular structure of 2,1,3-benzothiadiazole-4, 7 dicarbonitrile (BTDN).

When SAL is introduced to the system as the proton donor, the $\mathrm{CV}$ of BTDN (Figure 1a) is significantly perturbed. One can see that the first reduction peak shifts to a less negative potential as compared to that of the pure BTDN, which is characteristic of an EC (an electrochemical step E, followed by a chemical step C) type process ${ }^{19}$. This can be attributed to a single protonation of the $\mathrm{BTDN}^{-\cdot}$ species forming an organo-hydride species BTDNH'. Notably, the second redox peak completely disappears and gives way for a catalytic wave with the foot of the wave starting around $-1.6 \mathrm{~V}$ vs $\mathrm{Fc} / \mathrm{Fc}^{+}$. On the return scan, a tiny oxidation peak is observed, indicating that all or a majority of $\mathrm{BTDN}^{-}$has returned to its group species BTDN or has decomposed after catalytic proton reduction.

A titration of BTDN with SAL with CVs measured at every step was subsequently carried out. The corresponding data is shown in Figure 1a. The concentration of SAL was used from 2.5 to 50 equivalents. After passing two equivalents of acid all oxidative current from the second reduction disappears, meaning that all the reduced species have reacted at this point. Only a small amount of oxidative current is returned from the first reduction, the back current is expected to be from oxidation of $\mathrm{BTDN}^{-}$that has yet to react with acid during this time frame, implying slow reaction kinetics between $\mathrm{BTDN}^{-}$and SAL. This is also confirmed by Fourier-transform infrared spectroscopy (FTIR) 
which will be discussed later on (Figure 3a). At high acid concentrations $(\geq 8 \mathrm{mM})$ a curve crossing behavior has been observed in the catalytic wave at slower scan rates $\left(10 \mathrm{mV} \cdot \mathrm{s}^{-1}\right.$ $200 \mathrm{mV} \cdot \mathrm{s}^{-1}$, Figure S6). Curve crossing means that the catalytic current is higher on the return scan which is often indicative of build-up of the catalytic species during the scan. The phenomenon can be described by an ECE type reaction where the curve crossing appears when the chemical step is about the same rate as the scan rate ${ }^{20}$. The behavior here is attributed to two different processes first, non-catalytic degradation of SAL. After cycling in SAL the onset potential for the reductive wave moves to less reductive potentials (Figure S8) probably due to the formation of a layer on the working electrode, this current does not seem to be catalytic since very little hydrogen is detected from the bulk electrolysis experiment (Figure 1b). The second process could be the slow reaction kinetics between $\mathrm{BTDN}^{-\bullet}$ and SAL which would mean that the formation of organo-hydride species is not yet at equilibrium at the beginning of the catalytic wave.
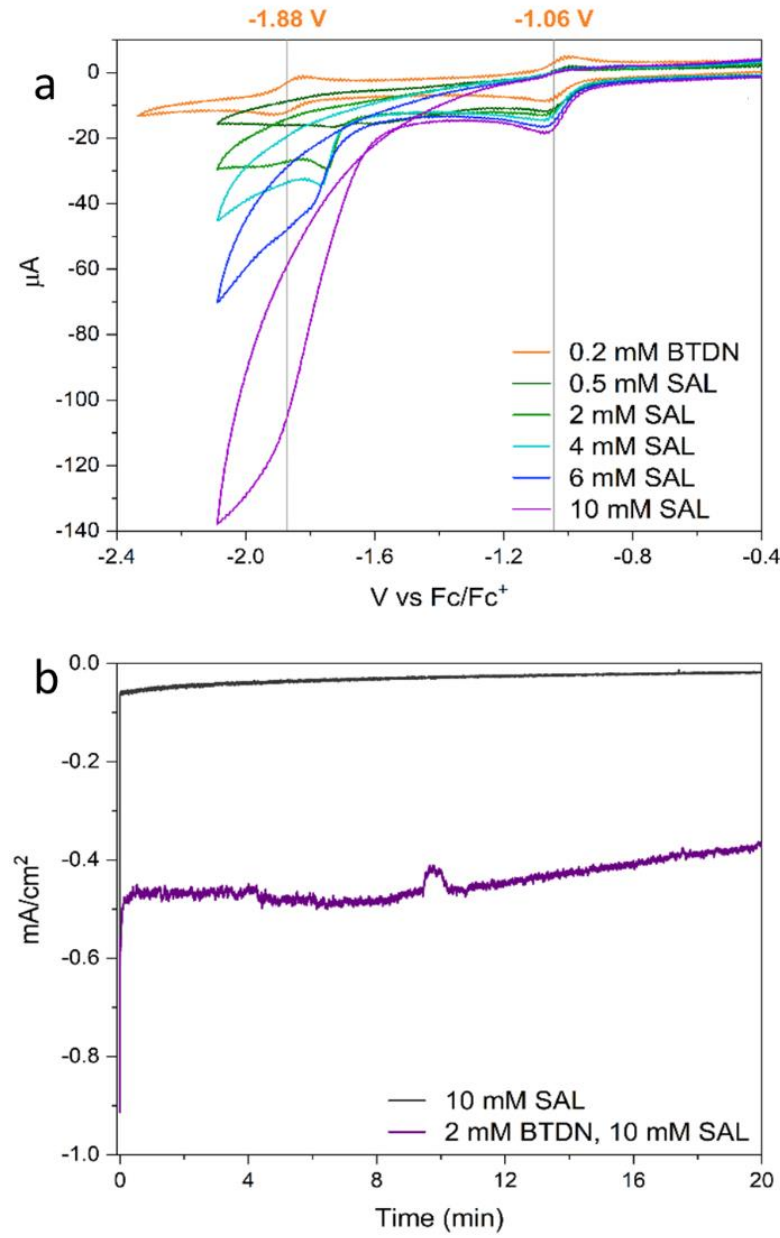

Figure 1: (a) Cyclic voltammetry of BTDN combined with titration of SAL. Goes from two reversible redox waves for only BTDN (orange) to the fully catalytic behaviour with 50 equivalents of SAL (Purple). (b) Current from electrocatalytic $\mathrm{H}_{2}$ generation at $-1.65 \mathrm{~V}$ vs $\mathrm{Fc} / \mathrm{Fc}^{+}$from 10 mM SAL (black) and $1 \mathrm{mM} \mathrm{BTDN}$ and $10 \mathrm{mM}$ SAL (purple).

To confirm that the catalytic wave appearing is in fact hydrogen evolution, bulk electrolysis experiments were conducted. The electrolysis was performed in the foot of the catalytic wave at $-1.65 \mathrm{~V}$ vs $\mathrm{Fc} / \mathrm{Fc}^{+}$to avoid large hydrogen evolution from bare SAL and glassy carbon electrode. In presence of BTDN (Figure $1 \mathrm{~b}$ ), a current density of $0.5 \mathrm{~mA} \cdot \mathrm{cm}^{-2}$ was achieved and only $20 \%$ decrease in current in 20 min was observed. Hydrogen evolution was also detected by gas chromatography and a faradaic efficiency was determined to be $82 \%$, some of the loss can be attributed to the degradation of SAL on the surface of the electrode or decomposition of some BTDN. Without BTDN, only $0.06 \mathrm{~mA} \cdot \mathrm{cm}^{-2}$ catalytic current was obtained and decreased rapidly. Only tiny amount of hydrogen was produced with a very low faradaic efficiency of $25 \%$. To appraise the TON of the catalyst, a longer experiment was run in a $3 \mathrm{ml}$ solution with 0.2 mM BTDN catalyst (Figure S9) which evolved $8.1 \mu \mathrm{mol} \mathrm{H}_{2}$, giving a TON of 13. This result suggests that the BTDN indeed works as a catalyst for electrocatalytic hydrogen production.
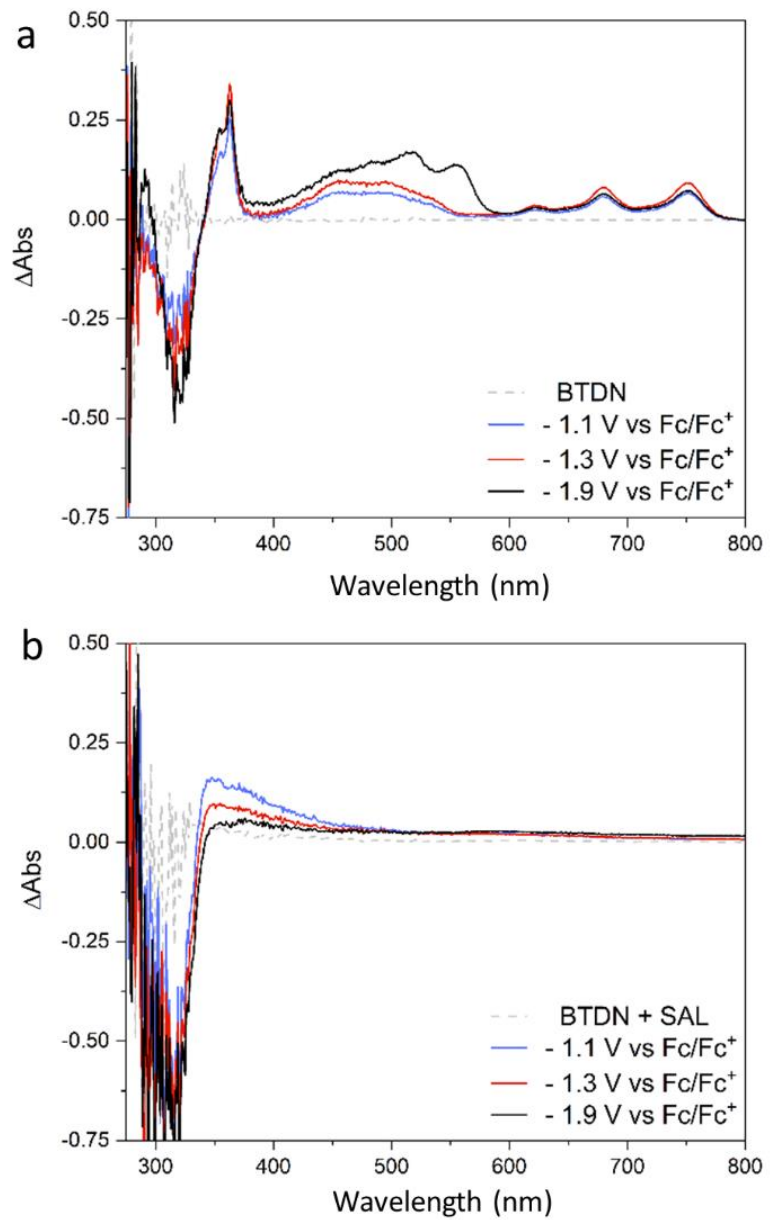

Figure 2: Difference spectra from UV-Vis SEC of BTDN (a) and BTDN with SAL (b) at three different potentials $-1.1 \mathrm{~V}$ (blue), $-1.3 \mathrm{~V}$ (Red) and $-1.9 \mathrm{~V}$ vs $\mathrm{Fc} / \mathrm{Fc}^{+}$(black).

In order to investigate the catalytic mechanism of BTDN for proton reduction, the reaction intermediates were attempted to monitor by electron paramagnetic resonance (EPR), spectroelectrochemistry (SEC), FTIR spectroscopy and nuclear magnetic resonance (NMR). Because of the EC nature of the first reduction peak in the catalytic cycle, the first intermediate is determined to be the $\mathrm{BTDN}^{-}$radical anion. The radical is also previously mentioned in literature and is incredibly stable ${ }^{17}$. The $\mathrm{BTDN}^{-}$radical was therefore generated through bulk electrolysis in an inert environment. EPR measurement of the $\mathrm{BTDN}^{-}$ (Figure S10) gave 27 splitting peaks. It means that the radical has hyperfine coupling to two $\mathrm{N}$ atom site. This result is in consistent with previously reported data and indicates that the radical is completely delocalized over the entire molecule ${ }^{17}$, which is also consistent with our DFT calculations (Figure S14). 
To further probe the intermediates during the catalytic cycle, SEC was performed in an inert atmosphere. First BTDN was studied in absence of the organic acid. The result is shown in Figure $2 \mathrm{a}$. One can see the characteristic absorption from $\mathrm{BTDN}^{-}$ is appeared when the applied potential $\left(-1.1 \mathrm{~V}\right.$ vs $\left.\mathrm{Fc} / \mathrm{Fc}^{+}\right)$reaches the first redox potential of BTDN. As compared to BTDN with an absorption maximum at $323 \mathrm{~nm}$ (Figure S11), the strongest absorption band of $\mathrm{BTDN}^{-}$is significantly red shifted and the radical has new characteristic absorption bands at 623,680 and $750 \mathrm{~nm}$. When a more negative potential $\left(-1.9 \mathrm{~V}\right.$ vs $\left.\mathrm{Fc} / \mathrm{Fc}^{+}\right)$is applied, the doubly reduced species $\mathrm{BTDN}^{2-}$ appeared with new absorption bands at 520 and $555 \mathrm{~nm}$. The absorption spectra of both $\mathrm{BTDN}^{-}$and $\mathrm{BTDN}^{2-}$ species were also confirmed by steady-state measurements on the species generated from bulk electrolysis (Figure S11). Subsequently, the SEC experiment in presence of 10 equivalents of SAL was carried out, as shown in Figure 2b. Notably, all features from $\mathrm{BTDN}^{-}$and $\mathrm{BTDN}^{2-}$ are completely vanished. Instead, there is new species with an absorption feature at $340 \mathrm{~nm}$ appearing at the potential of $-1.1 \mathrm{~V}$ vs $\mathrm{Fc} / \mathrm{Fc}^{+}$, which is attributed to the protonation of $\mathrm{BTDN}^{-}$to form an organic hydride species (BTDNH $\left.{ }^{\circ}\right)$, this feature is also seen in steady state measurements (Figure S11). Moving into a more negative potential of $-1.3 \mathrm{~V}$ vs $\mathrm{Fc} / \mathrm{Fc}^{+}$, the absorption started to decline in intensity. When a catalytic potential of $-1.9 \mathrm{~V}$ vs $\mathrm{Fc} / \mathrm{Fc}^{+}$is applied, the feature was completely disappeared, which is probably attributed to the reformation of the BTDN after catalysis. The bleach at $320 \mathrm{~nm}$ could be from decomposition of SAL which absorbs in this region ${ }^{23}$, and probably also from decomposition of some BTDN during the catalytic cycle.

FTIR was used to characterize different intermediates generated from the bulk electrolysis. The corresponding data is shown in Figure 3. To follow the changes of the molecule, the stretching mode of the $\mathrm{C} \equiv \mathrm{N}$ bond is used as an IR probe as it has a well-characteristic absorption peak in the IR region ${ }^{24}$. the stretching mode of BTDN absorbs quite weakly as a singular peak at $2235 \mathrm{~cm}^{-1}$. When BTDN was reduced to $\mathrm{BTDN}^{-}$, the absorption peak shifted to a lower value of $2184 \mathrm{~cm}^{-1}$. Such a shift is resulted from the delocalized nature of the radical, making the nitrile bond as a part of the conjugated system in BTDN. This also leads to that intensity of the nitrile stretching absorption becomes much stronger, about 10 times as compared to that of the BTDN. When one equivalent of SAL was added to $\mathrm{BTDN}^{-}$ solution, the $2184 \mathrm{~cm}^{-1}$ peak started to disappear; meanwhile, two new peaks at $2235 \mathrm{~cm}^{-1}$ and $2217 \mathrm{~cm}^{-1}$ appeared. The reaction between $\mathrm{BTDN}^{-}$and SAL seems very slow. Assumed a first order kinetic from both compounds and plotted the disappearance of the $2184 \mathrm{~cm}^{-1}$ peak versus time, a rate constant of $12 \mathrm{~s}^{-1}$ can be derived (Figure $\mathrm{S} 11$ ).

The new peaks could be attributed to the BTDNH ${ }^{\bullet}$ species where the split peaks are due to the asymmetry of the new species if the $\mathrm{N}$ atom in hetero-ring of $\mathrm{BTDN}^{-*}$. The absorption band at $2235 \mathrm{~cm}^{-1}$ can be attributed to the mostly unperturbed stretching of the $\mathrm{CN}$ that is located far away from the pronated $\mathrm{N}$. The other band at $2217 \mathrm{~cm}^{-1}$ is the starching of $\mathrm{CN}$ closer to the protonated nitrogen. To have further evidence that it is the BTDNH ${ }^{\bullet}$ species or not decomposed BTDN, proton NMR of the three species were measured (Figure S12). Normal BTDN shows a single peak in aromatic region. When BTDN is reduced to $\mathrm{BTDN}^{-}$, the aromatic peak is vanished during that region because of the paramagnetic nature of the $\mathrm{BTDN}^{-\cdot}$ radical. Following addition of SAL to the $\mathrm{BTDN}^{-}$solution, the peaks in the aromatic region does not appear, indicating that the protonated compound is still paramagnetic and should be a pronated radical species, probably the BTDNH'.

Considering all the possible protonated species from BTDN ${ }^{-}$, DFT calculations were applied. From the calculated IR spectra
(Figure $3 \mathrm{~b}$ ) both protonation on the $\mathrm{N}$-site and S-site on the BT unit seem to have a splitting similar to the experimental one. When comparing the free binding energy, $\Delta \mathrm{G}$, of the two possible species, it is clear that protonation on the $\mathrm{N}$-site is by far the most likely scenario (Figure $3 \mathrm{~b}$ and Figure S15), because the protonation of $\mathrm{S}$ has much larger $\Delta \mathrm{G}$ than that of the pronation of N. However, the intermediates of the final catalytic step were not captured experimentally due to the fast reaction rate. Therefore, it is hard to confirm the protonation site when the second proton comes to the final catalytic step, more advanced experiments are therefore required in the future.
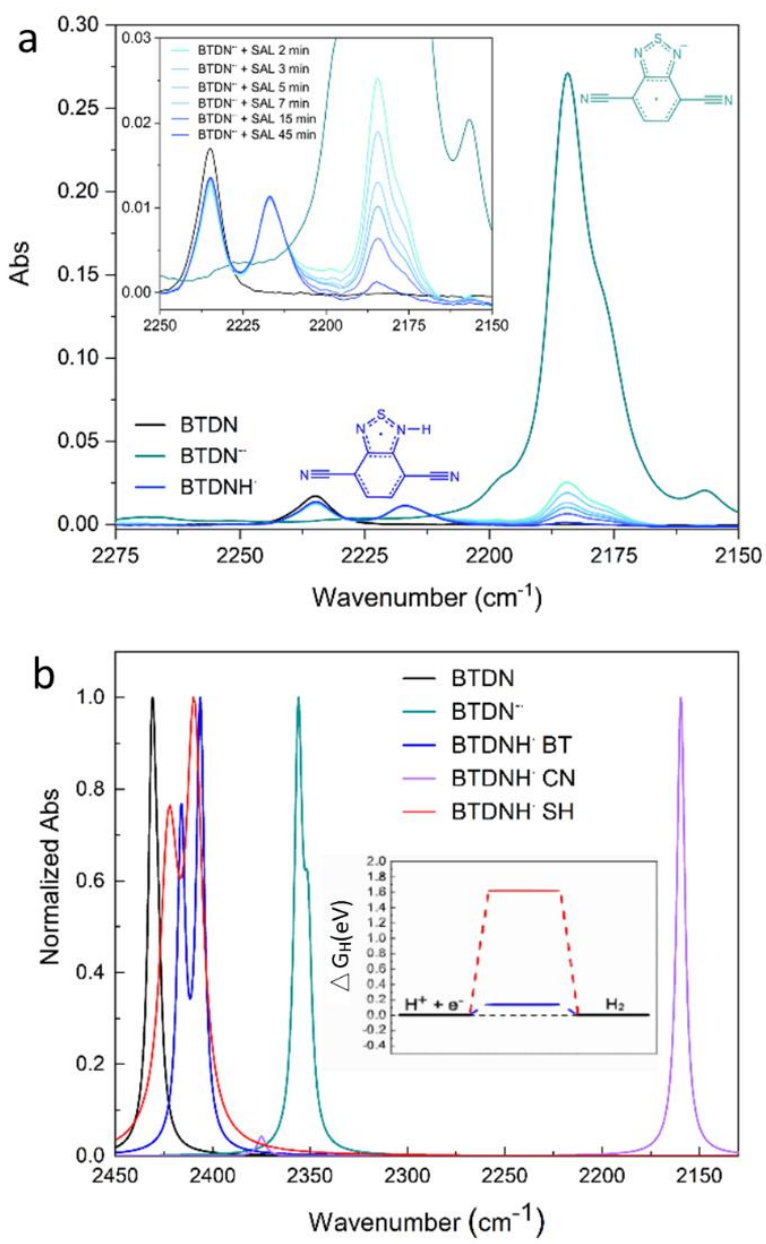

Figure 3. Experimental (a) and calculated (b) FTIR spectra of the catalytic intermediates, (a) BTDN (black), BTDN ${ }^{-*}$ (teal), BTDNH'(blue) and transitions in between the intermediates. Inset showing a zoom in on the decline of $\mathrm{BTDN}^{-}$and growth of $\mathrm{BTDNH}^{*}$ species after the addition of 1 equivalent of SAL. (b) BTDN (black), BTDN"'(teal) and for the protonated reduced state/radical considering three possible sites for protonation: at the $\mathrm{N}$ atom from the $\mathrm{BT}$ unit (blue), at the $\mathrm{N}$ atom from the $\mathrm{CN}$ group (pink) and at the $\mathrm{S}$ atom (red). Inset showing the $\Delta \mathrm{G}$ of the protonation on the $\mathrm{N}$ atom and $\mathrm{S}$ atom for the HER. Spectra extracted from DFT calculation at M06/6-311G(d,p) theory level.

Combining experimental and theoretical data, an electrocatalytic mechanism for hydrogen evolution from BTDN is therefore proposed, as shown in Figure 4. Firstly, BTDN is reduced to $\mathrm{BTDN}^{-}$and followed by protonation of $\mathrm{BTDN}^{-}$ radical anion at the $\mathrm{N}$-site via an $\mathrm{EC}$ reaction in the presence of an acid to form an organic hydride radical BTDNH*. Subsequently, BTDNH ${ }^{*}$ is further reduced and the final catalysis happens with another proton. As a more reductive voltage is 
needed to get into the final catalytic wave, indicating an ECEC type mechanism for the full reaction. As no hydrogen was detected from just BTDNH${ }^{*}$ species, it indicates that the second reduction is necessary for the catalytic process, further strengthening the proposed ECEC mechanism.

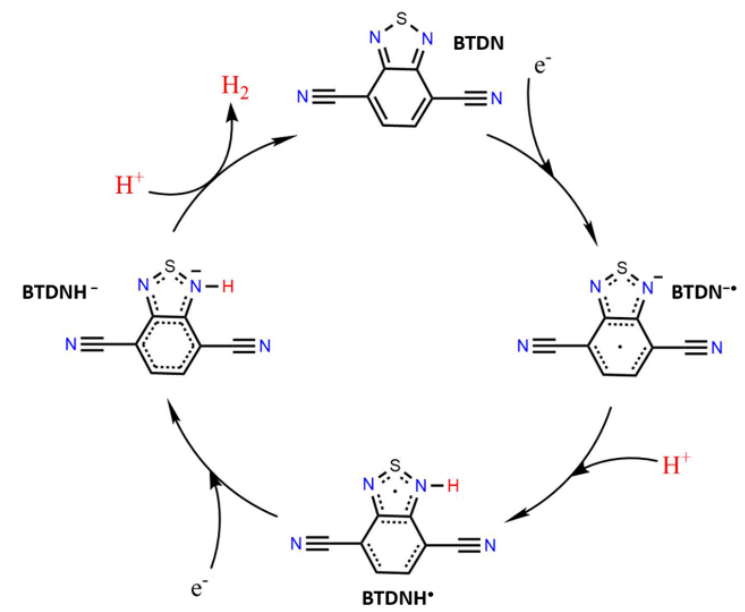

Figure 4. The proposed catalytic mechanism for hydrogen evolution from BTDN. Showcasing the ECEC type mechanism

In summary, we have demonstrated a small organic molecule 2,1,3-benzothiadiazole-4, 7-dicarbonitrile (BTDN) that can act as a catalyst for electrocatalytic hydrogen evolution. Some reaction intermediates have been successfully captured and well characterized by EPR, UV-Vis SEC, IR and NMR. Combining the experimental data with theoretical DFT calculation, the first protonation of the reduced BTDN is confirmed to happen on $\mathrm{N}$ atom in its heteroatom ring. Eventually, an electrocatalytic mechanism of BTDN for hydrogen production is proposed. This work paves a road for development of small organic catalyst for hydrogen production. The result is also helpful to understand the role of benzothiadiazole unit in some functional materials such as covalent organic framework and mesoporous organic semiconducting polymers used for electro- or photo-catalytic hydrogen production. More research work on understanding the final catalytic step of BTDN for hydrogen production and studying the effect of BTDN type molecular structures on catalytic hydrogen evolution, $\mathrm{CO}_{2}$ reduction and organic photoredox catalysis is ongoing.

\section{ASSOCIATED CONTENT}

Supporting information includes experimental details; control experiments; calculation of TON; EPR spectrum; determination of rate constant and the computational method/results. This material is available free of charge via the Internet at http://pubs.acs.org.

\section{AUTHOR INFORMATION}

\section{Corresponding Author}

Haining Tian, haining.tian@kemi.uu.se

\section{Funding Sources}

Swedish Research Council (grant no. 2017-03757, 2020-05223).

\section{ACKNOWLEDGMENT}

We gratefully thank the financial support from Swedish Research Council (grant no. 2017-03757, 2020-05223). CFNM and CMA thank the Swedish National Infrastructure for Computing (SNIC) at the PDC Center for High-Performance Computing and National Supercomputer Center at Linköping University (NSC); and additional financial support by Swedish Energy Agency (grant no. 45420-1) and STandUP for Energy collaboration.We greatly thank Dr. Reiner Lomoth, Dr. Brian McCarthy and Dr. Mun Hon Cheah for insightful discussions.

\section{REFERENCES}

(1) Hammarström, L.; Hammes-Schiffer, S. Acc. Chem. Res., 2009, 12, 1859-1860.

(2) Razavet, M.; Artero, V.; Fontecave, M. Inorganic Chemistry, 2005 44, 4786-4795.

(3) Brardi, S.; Drouet, S.; Francàs, L.; Gimbert-Suriñach, C.; Guttentag, M.; Richmond, C.; Stolla T.; Llobet, A. Chem. Soc. Rev., 2014, 43, 75017519 .

(4) Greeley, J.; Jaramillo, T. F.; Bonde, J.; Chorkendorff, I.; Nørskov J. K. Nat. Mater., 2006, 5, 909-913.

(5) Wang, Y.; Vogel, A.; Sachs, M.; Sprick, R. S.; Wilbraham, L.; Moniz, S. J. A.; Godin, R. ; Zwijnenburg, M. A.; Durrant, J. R.; Cooper A. I.; Tang, J. Nat. Energy., 2019 , 4, 746-760.

(6) Mirzakulova, E.; Khatmullin, R.; Walpita, J.; Corrigan, T.; VargasBarbosa, N. M.; Vyas, S.; Oottikkal, S.; Manzer, S. F.; Hadad, C. M.; Glusac, K. D.; Nat. Chem., 2012, 4, 794-801.

(7) Li, H.; Xie, F.; Ming-Tian, Z. ACS Catal., 2021, 11, 68-73.

(8) Ilic, S.; Pandey Kadel, U.; Basdogan, Y.; Keith, J. A.; Glusac, K. D. J. Am. Chem. Soc., 2018, 140, 4569-4579.

(9) Lim, C.-H.; Ilic, S.; Alherz, A.; Worrell, B. T.; Bacon, S. S.; Hynes, J. T.; Glusac, K. D.; Musgrave, C. B. J. Am. Chem. Soc., 2019, 141, $272-280$.

(10) Boston, D. J.; Xu, C.; Armstrong, D. W.; MacDonnell, F. M. J. Am. Chem. Soc., 2013, 135, 16252-16255.

(11) Lim, C. -H.; Holder, A. M.; Hynes, J. T.; Musgrave, C. B. J. Am. Chem. Soc. 2014, 136, 45, 16081-16095.

(12) Vasilyev, D. V.; Dyson, P. J. ACS Catal. 2021, 11, 3, 1392-1405.

(13) Baumgartel, H.; Retzlav, K.-J.; Bard, A. J.; Dekker, M. Heteroaromatic Compounds. In Encyclopedia of Electrochemistry of the Elements $X V, \mathbf{1 9 8 4}, 194$, New York.

(14) Pati, P. B.; Damas, G.; Tian, L.; Fernandes, D. L.; Zhang, L.; Pehlivan, I. B.; Edvinsson, T. ; Araujo, C. M.; Tian, H. Energy Environ. Sci., 2017, 10, , 1372-1376.

(15) Yang, C.; Chiyin Ma, B.; Zhang, L.; Lin, S.; Ghasimi, S.; Landfester, K.; Zhang, K. A. I.; Wang, X. Angew. Chem., 2016, 128, 9348 -9352 .

(16) Wang, L.; Fernández-Terán, R.; Zhang, L.; Fernandes, D. L. A.; Tian, L.; Chen, H.; Tian, H.; Angew. Chem. Int. Ed., 2016, 55, $12306-$ 12310 .

(17) Camilleri, P.; Dearing, A.; Cole-Hamilton D. J.; O'Neill, P. J. Chem. Soc., 1986, 2,.569-572.

(18) Dainty, C.; Bruce, D. W.; Cole-Hamilton and P. Camilleri, J. Chem. Soc., Chem. Commun., 1984, 860, 1324-1325.

(19) Robinson, J. N.; Camilleri, P.; Dainty, C.; Maxwell, V.; ColeHamilton, D. J. J. Chem. Soc., Faraday Trans. I, 1989, 85, 3385-3394.

(20) Kütt, A.; Leito, I.; Kaljurand, I.; Sooväli, L.; Vlasov, V. M.; Yagupolskii, L. M.; Koppel, 1. A.; J. Org. Chem., 2006, 71, 2829-2838.

(21) Nicholson, R. S.; Shain, I. Anal. Chem., 1964, 36, 706-723.

(22) Savéant, J.-M. Elements of Molecular and Biomolecular Electrochemistry, 2006, John Wiley \& Sons Inc.

(23) Salinas, F.; Berzas Nevada, J. J.; Espinosa Mansilla, A. Talanta, 1990, 37, 347-351.

(24) Griffith, R. E.; Kitson, N. E. Anal. Chem., 1952, 24, 334-337. 


\section{TOC}

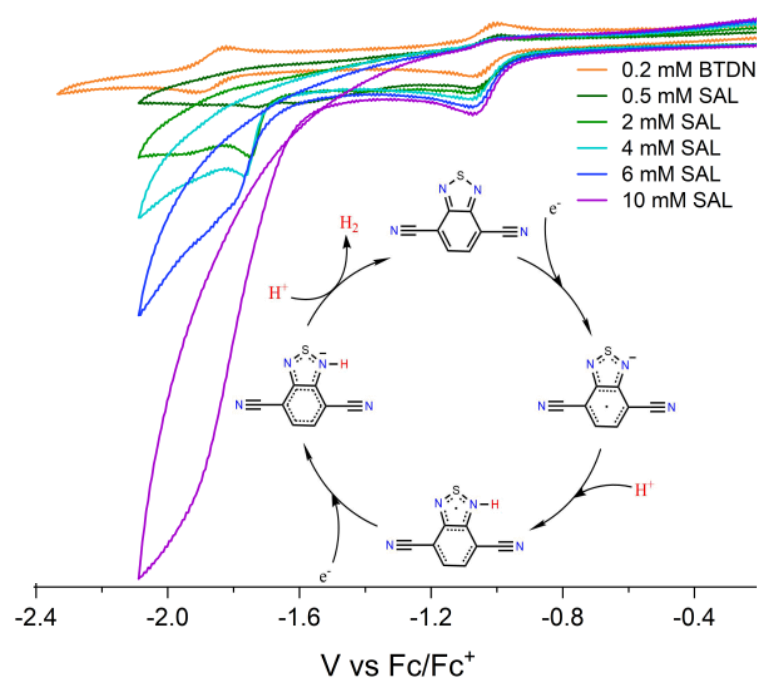

